\title{
Solid-State Carbon NMR Characterization and Investigation of Intrinsic Dissolution Behavior of Fluconazole Polymorphs, Anhydrate Forms I and II
}

\author{
Hee Jun Park, Min-Soo Kim, Jeong-Soo Kim, Wonkyung Cho, Junsung Park, Kwang-Ho Cha, \\ Young-Shin KANG, and Sung-Joo HwanG* \\ Center for Nanotechnology-Based New Drug Dosage Form, College of Pharmacy, Chungnam National University; 220 \\ Gung-dong, Yuseong-gu, Daejeon 305-764, Republic of Korea. \\ Received April 7, 2010; accepted May 31, 2010; published online June 23, 2010
}

\begin{abstract}
Solid-state ${ }^{13} \mathrm{C}$ nuclear magnetic resonance $\left({ }^{13} \mathrm{C}\right.$-SSNMR) revealed significant differences in the chemical shift of specific carbon atoms between two fluconazole polymorphs, reflecting a change in molecular conformation. A single resonance signal without splitting was observed in the spectrum of anhydrate form II, while the spectrum of anhydrate form I showed signals with splitting, indicating the presence of two dissimilar molecular conformations in the unit cell of anhydrate form I. The Fourier transform infrared (FT-IR) and Raman spectra associated with the triazole group, the 2,4-difluorobenzyl group, and the propane backbone provided also evidence of structural differences between forms I and II accompanying with ${ }^{13} \mathrm{C}-S S N M R$. ${ }^{1} \mathrm{H} T_{1}$ relaxation times, measured using saturation recovery experiments, showed that the metastable anhydrate form II was more mobile than the stable form I. The solubility and intrinsic dissolution tests showed that the anhydrate form II was more soluble and dissolved faster than the anhydrate form $I$.
\end{abstract}

Key words fluconazole; polymorph; solid-state nuclear magnetic resonance; solubility; intrinsic dissolution rate

Polymorphism is defined as the occurrence of different crystalline forms of the same pure compound in which the molecules have different arrangement and/or conformation. ${ }^{1)}$ Many drugs are able to be crystallized in several polymorphic forms, each having a different energy and thereby differing in physicochemical and mechanical properties such as melting point, solubility, stability, heat of fusion, density, refractive index, compression behavior and hygroscopicity. ${ }^{2}$ Supercritical fluid (SCF) based technologies are currently valid tools among various crystallization techniques to control the polymorphic form of pharmaceuticals. ${ }^{3)}$ The differences of properties such as solubility may have implications for absorption of the active drug from its dosage form. These concerns have led to an increased regulatory interest in the solid-state properties. ${ }^{4,5}$ Solid state NMR (SSNMR) spectroscopy is also an essential technique for the solid state characterization of pharmaceuticals. The SSNMR spectroscopy not only differentiates between polymorphic forms of a pharmaceutical, but also intimately probes the structural aspects of polymorphic form. ${ }^{6)}$ Furthermore, solid state proton relaxation time $\left(T_{1}\right)$ studies can also provide useful information on molecular motion in the solid state. ${ }^{7)}$

Intrinsic dissolution test is a one of the attempt to measure the solubility of a metastable polymorph which can undergo a phase transformation to the more stable phase during dissolving procedure. In fact, equilibrium solubility may not be very relevant for study of polymorphs if polymorphs are physically unstable in the aqueous environment. Instead, intrinsic dissolution rate (IDR) and kinetic solubility may be more relevant parameters to consider while studying the oral absorption of polymorphs., ${ }^{2,8,9)}$

Fluconazole is designated chemically as 2,4-difluoro$\alpha, \alpha^{1}$-bis(1H-1,2,4-triazol-L-ylmethyl) benzyl alcohol (Fig. 1) and is the first of a new subclass of synthetic triazole antifungal agent. ${ }^{10)}$ Three anhydrate polymorphic forms, one monohydrate and several solvates of fluconazole, have been prepared and characterized. ${ }^{11-20)}$ However, there has been no

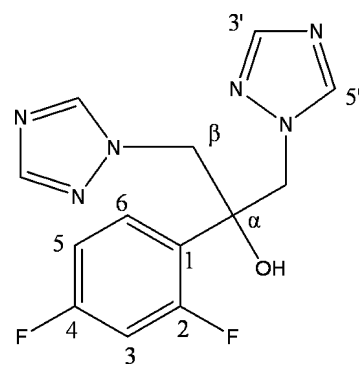

Fig. 1. Chemical Structure of Fluconazole

published research involving the characterization of fluconazole polymorphs using SSNMR spectroscopy.

Consequently, we investigate the characterization of two fluconazole polymorphs, anhydrate forms I and II prepared by the supercritical antisolvent (SAS) process using SSNMR spectroscopy to obtain the structural differences in molecular level between fluconazole polymorphs. General solid state characterization such as differential scanning calorimetry (DSC), Powder X-ray diffraction (PXRD), fourier transform infrared (FT-IR) and Raman spectroscopy were also performed. Furthermore, kinetic solubility and intrinsic dissolution tests in aqueous solution were performed to investigate the solubility profiles and dissolution properties of fluconazole polymorphs.

\section{Experimental}

Materials Micronized fluconazole ( $99.0 \%$ purity) was kindly provided Hwail Pharm. Co., Ltd. (Korea). The $\mathrm{CO}_{2}$ used was $99.9 \%$ pure (Hanmi Gas, Korea). Deuterodimethyl sulfoxide (DMSO- $d_{6}$ ) was obtained from Cambridge Isotope Laboratories, Inc. (U.S.A.). All organic solvents were of high performance liquid chromatography (HPLC) grade and other chemicals were of reagent grade.

Preparation of Fluconazole Polymorphs The anhydrate forms I and II were prepared by the SAS process reported in the earlier study at simply modified conditions. ${ }^{20)}$ The flow rate of dichloromethane drug solution was varied between $0.5 \mathrm{ml} / \mathrm{min}$ and $3.5 \mathrm{ml} / \mathrm{min}$, while the flow rate of $\mathrm{CO}_{2}$ was constant at $40 \mathrm{ml} / \mathrm{min}$. The temperature and pressure of the SAS process 
were constant at $40^{\circ} \mathrm{C}$ and $8 \mathrm{MPa}$. Fluconazole monohydrate was obtained using cooling method reported by Alkhamis et al. ${ }^{17)}$

Analysis and Characterization Residual solvent was measured by a gas chromatograph (Agilent technologies, Agilent 6890, U.S.A.) equipped with a flame ionization detector (GC-FID) system. DSC measurements were generated using DSC S-650 (Scinco Co., Ltd., Korea). PXRD patterns were obtained by a Rigaku PXRD system (Model D/MAX-2200 Ultima/PC, Japan) using a Ni-filtered $\mathrm{Cu} K \alpha$ radiation source. The ${ }^{13} \mathrm{C}$-SSNMR crosspolarization magic angle spinning (CP/MAS) and high-power proton decoupling experiment was recorded on a Bruker AVANCE $400 \mathrm{WB}$ (Bruker, Germany) at $500 \mathrm{MHz}$ and ambient probe temperature. The MAS rate was set at $9 \mathrm{kHz}$, with a contact time of $1 \mathrm{~ms}$ and an acquisition time of $0.036 \mathrm{~s}$. Recycle delays to acquire standard spectra varied based upon ${ }^{1} \mathrm{H} T_{1}$ measurement. ${ }^{1} \mathrm{H} T_{1}$ relaxation times were measured using saturation recovery experiments. The solution state ${ }^{13} \mathrm{C}$-NMR spectra were also obtained from deuterodimethyl sulfoxide (DMSO- $d_{6}$ ) solutions of samples using a JNM-AL400 (JEOL Ltd., Japan) at $400 \mathrm{MHz}$. FT-IR spectroscopy was performed on a FTIR spectrometer (Bruker, FT-IR Tensor 27, Germany) using the attenuated total reflectance (ATR) method. The Raman spectra were measured with a Spex 1404p spectrometer (Jobinyvon-Spex, France). The excitation source was a $\mathrm{He}-\mathrm{Cd}$ laser operating at $442 \mathrm{~nm}$. Intrinsic dissolution test were performed by the stationary disc $\left(0.5 \mathrm{~cm}^{2}\right.$ surface area, Distek Inc., U.S.A. $)$ and VK 7000 dissolution apparatus (Vankel, U.S.A.) according to USP XXVIII paddle method. Discs were prepared compressing $300 \mathrm{mg}$ of powder in a Perkin Elmer hydraulic press, for 4 min under 2000 psi compression. The solubility of fluconazole was determined in deionized water at $25 \pm 0.1^{\circ} \mathrm{C}$ An excess amount of each sample (approximately $1 \mathrm{~g}$ of fluconazole) was added separately to $50 \mathrm{ml}$ of water in a screw-top bottle. The bottles were dispersed using sonicator $(10 \mathrm{~min})$ and rotated $(30 \mathrm{rpm})$ for a period of time in excess of that required for equilibrium $(48 \mathrm{~h})$ using a shaking water bath at $25 \pm 0.1^{\circ} \mathrm{C}$. Intrinsic dissolution tests were performed in distilled water at $25 \pm 0.1^{\circ} \mathrm{C}$ and $50 \mathrm{rpm}$ by the stationary disc $\left(0.5 \mathrm{~cm}^{2}\right.$ surface area, Distek Inc., U.S.A.) and VK 7000 dissolution apparatus (Vankel, U.S.A.) according to USP XXVIII paddle method. Drug concentration was assayed for drug concentration by UV spectrophotometer (262 nm) (Beckman, DU-650, U.S.A.).

\section{Results and Discussion}

The DSC thermograms and PXRD patterns were shown in Fig. 2. Anhydrate form I was prepared at fast injection rates $(3.5 \mathrm{ml} / \mathrm{min})$. On the other hand, anhydrate form II was prepared at a slow injection rate $(0.5 \mathrm{ml} / \mathrm{min}) .{ }^{17,20)}$ GC-FID analysis, used to measure residual solvent in samples prepared by the SAS process, revealed a residue below $50 \mathrm{ppm}$.

The ${ }^{13} \mathrm{C}-\mathrm{SSNMR}$ spectra of the polymorphs prepared by the SAS process are compared in Fig. 3 and Table 1. There are two spectral regions, which show clear differences between the anhydrate forms I and II in the ${ }^{13} \mathrm{C}$-SSNMR spectra. The first region of interest is $50-80 \mathrm{ppm}$, which arises from $\alpha$-quaternary carbon and two $\beta$-methylene carbon atoms of the propane backbone. The peak arising from the hydroxyl-substituted $\alpha$-quaternary carbon of anhydrate form I is clearly split into a doublet ( $\delta: 73.928,75.305 \mathrm{ppm})$, but the peak of this carbon is only a singlet $(\delta: 74.132)$ for anhydrate form II. Additionally, the peak corresponding to two $\beta$ methylene carbon atoms shows significant differences in the chemical shift and intensity ratios between forms I and II. The second region of interest is the 2,4-difluorobenzyl group between $100-140 \mathrm{ppm}$. The peak arising from C-1 of anhydrate form I was split into doublets, which is not the case for form II. Additionally, the peaks corresponding to C-3 and C5 in form II are shifted by about 4.3 and 2 ppm, respectively, when compared with form I. These spectral differences in these regions could indicate different chemical environments, producing differing levels of the de-shielding effect of the electronic density, accompanied by differences in some molecular interactions and crystal symmetry. ${ }^{21)}$ SSNMR spectroscopy can be used to estimate the number of molecular conformations, as well as the configurational differences, in a portion of the molecule. ${ }^{22,23)}$ The ${ }^{13} \mathrm{C}$-SSNMR spectra of anhydrate form II shows only one peak per carbon atom with no peak splitting. However, the number of form I peaks exceeds the number of carbon with splittings of the $\alpha$-quaternary carbon and C-1 of 2,4-difluorobenzyl groups. The splitting pattern indicates a different level of deshielding produced by two different chemical environments. This suggests that two dissimilar molecular conformations or asymmetric units are present in the unit cell of anhydrate form I, while only one molecular conformation is presented in anhydrate form II. SSNMR spectroscopy results coincide well with the results of FT-IR, Raman spectroscopy (Fig. 4, Table 2) and PXRD analysis (Fig. 2) that show differences in molecular structure and crystal packing arrangement between different polymorphic forms of fluconazole. A comparison between
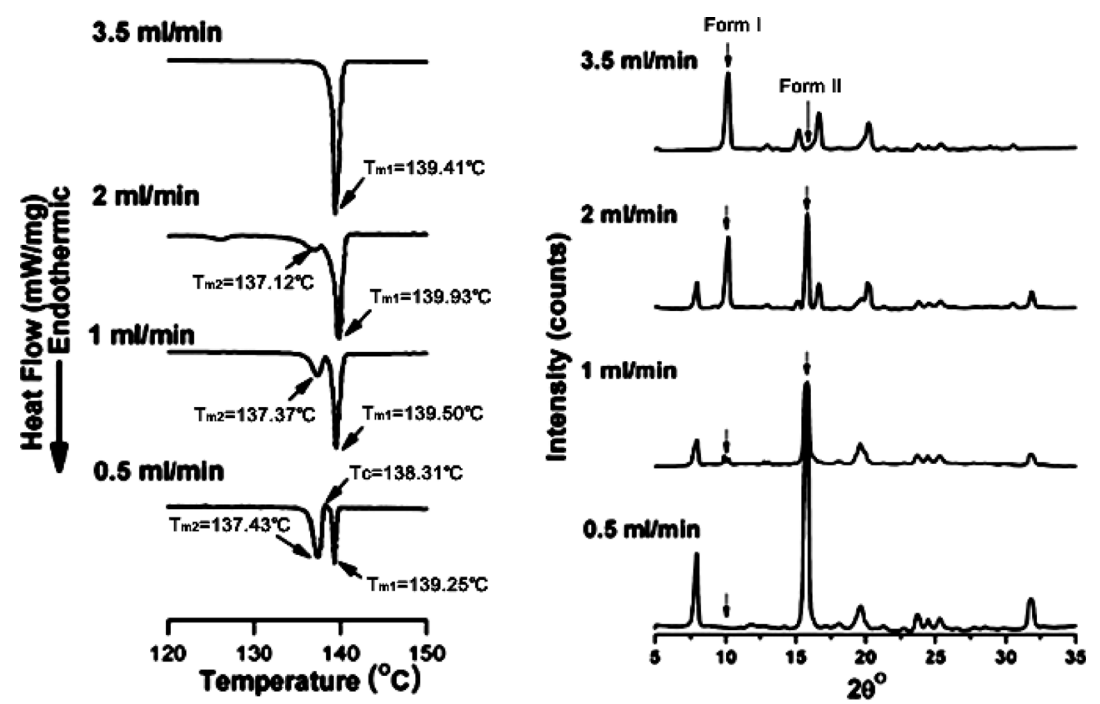

Fig. 2. DSC Thermograms (Left) and PXRD Patterns (Right) of Fluconazole Prepared by the SAS Process at Various Injection Rates of Drug Solution

$T_{\mathrm{m} 1}$ and $T_{\mathrm{m} 2}$ correspond to the melting temperature of anhydrate forms I and II, respectively, and $T_{\mathrm{c}}$ corresponds to the recrystallization exothermic temperature of unstable anhydrate form II. 
the ${ }^{13} \mathrm{C}$ chemical shifts for fluconazole in solution and solid states is shown in Table 1 . The ${ }^{13} \mathrm{C}$ solution spectrum of fluconazole is more closely related to the ${ }^{13} \mathrm{C}$-SSNMR spectrum of anhydrate form I, comparable to that of anhydrate form II.
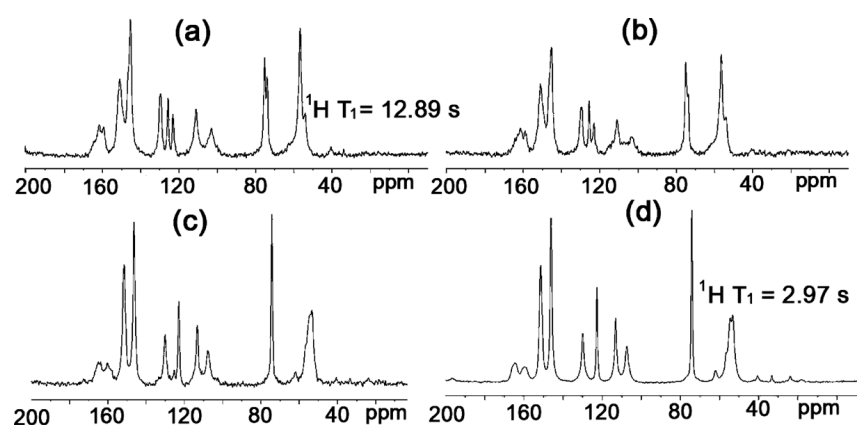

Fig. 3. ${ }^{13} \mathrm{C}-\mathrm{CP} / \mathrm{MAS}$ SSNMR Spectra of Fluconazole Polymorphs Prepared by the SAS Process at Various Injection Rates of Drug Solution

(a) Anhydrate form I, mixture of anhydrate forms I and II; (b) higher content of an hydrate form I than II, (c) higher content of anhydrate form II than I, and (d) anhydrate form II.

Table 1. Solid State ${ }^{13} \mathrm{C}$ CP/MAS NMR Peaks of Anhydrate Forms I and II Prepared by the SAS Process

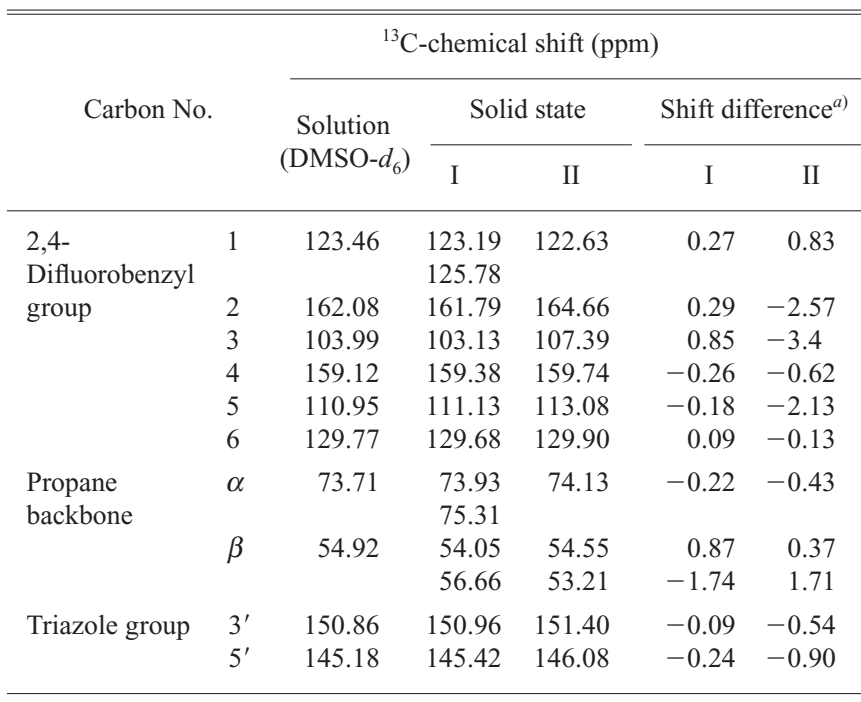

a) The difference between solution and solid state chemical shift data.
Therefore, the conformation of the molecules in solution is similar to the more stable polymorphic form, anhydrate form I, than to the metanstable polymorphic form, anhydrate form II. Analysis of ${ }^{1} \mathrm{H} T_{1}$ relaxation times also reveals differences between anhydrate forms I and II (Fig. 3). The shorter ${ }^{1} \mathrm{H} T_{1}$ of anhydrate form II (2.97 s) is attributed to increased mobility relative to anhydrate form I $(12.89 \mathrm{~s})$, possibly resulting from a partial or regional disruption of the crystal lattice. ${ }^{8)}$ This result is in agreement with the fact that the metastable polymorphs are typically much more mobile than relatively stable polymorphs, and, thus, are able to relax much faster.

As shown in Fig. 5 and Table 3, the maximum solubility (approximately $6.59 \mathrm{mg} / \mathrm{ml}$ ) was observed in anhydrate form II and then it was gradually decreased, suggesting that solution-mediated transformation to most stable polymorphic form, fluconazole monohydrate, occurred during the dissolution in water. ${ }^{4,24-26)}$ On the other hands, the kinetic solubility curve of anhydrate form I and fluconazole monohydrate reached the plateau without convex curve (approximately $4.96,4.21 \mathrm{mg} / \mathrm{ml}$, respectively). Interestingly, partial polymorphic change of anhydrate form I was observed during the

Table 2. FT-IR and Raman Peaks of Anhydrate Forms I and II Prepared by the SAS Process

\begin{tabular}{|c|c|c|c|c|}
\hline \multirow{3}{*}{ Assignment } & \multicolumn{4}{|c|}{ Wavenumber $\left(\mathrm{cm}^{-1}\right)$} \\
\hline & \multicolumn{2}{|c|}{ Anhydrate form I } & \multicolumn{2}{|c|}{ Anhydrate form II } \\
\hline & FT-IR & Raman & FT-IR & Raman \\
\hline \multicolumn{5}{|l|}{ 2,4-Difluorobenzyl group } \\
\hline \multirow[t]{4}{*}{$\mathrm{CH}$ stretch } & 3105.1 & 3083.8 & 3104.6 & 3072.6 \\
\hline & - & - & 3077.6 & 3099.9 \\
\hline & 3051.1 & 3010.8 & 3046.7 & 3024.4 \\
\hline & 3014.5 & - & 3027.4 & 3000.9 \\
\hline CF stretch & 1272.9 & 1276.5 & 1275.4 & 1266.6 \\
\hline \multicolumn{5}{|l|}{ Propane backbone } \\
\hline $\mathrm{CH}$ bend & very weak & & 1356.5 & \\
\hline $\mathrm{C}-\mathrm{C}$ stretch & 1116.7 & $\begin{array}{l}1117.6 \\
1112.9\end{array}$ & 1121.7 & 1116.7 \\
\hline $\begin{array}{l}\mathrm{C}-(\mathrm{OH}) \text { stretch } \\
\mathrm{H} \text {-bonded } \mathrm{OH} \text { stretch }\end{array}$ & 1026.0 & 1021.3 & 1024.6 & $\begin{array}{l}1023.5 \\
3192.7\end{array}$ \\
\hline
\end{tabular}

\section{FT-IR}
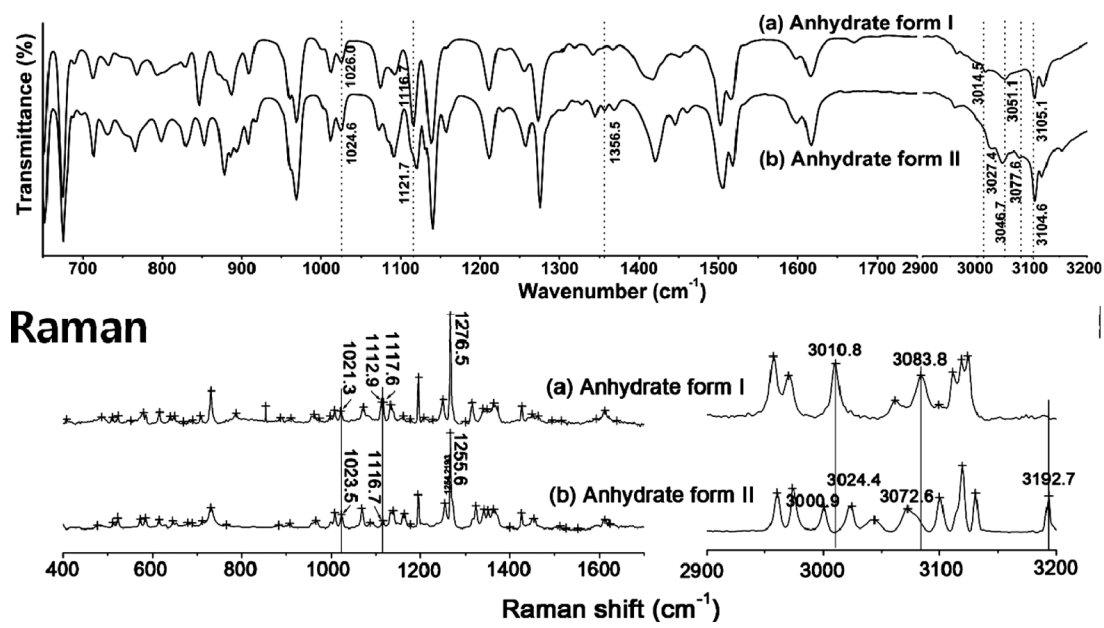

Fig. 4. FT-IR and Raman Spectra of Fluconazole Polymorphs Prepared by the SAS Process

(a) Anhydrate form I and (b) anhydrate form II. 
(a)

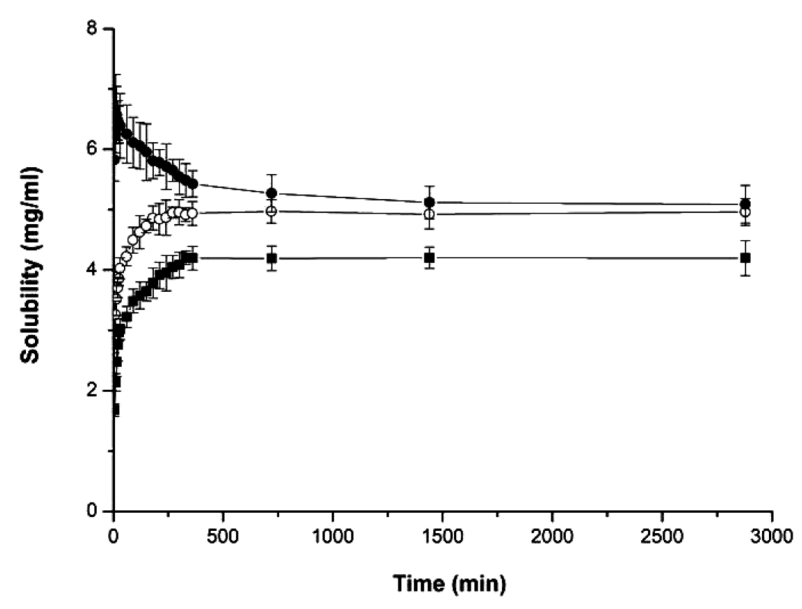

(b)

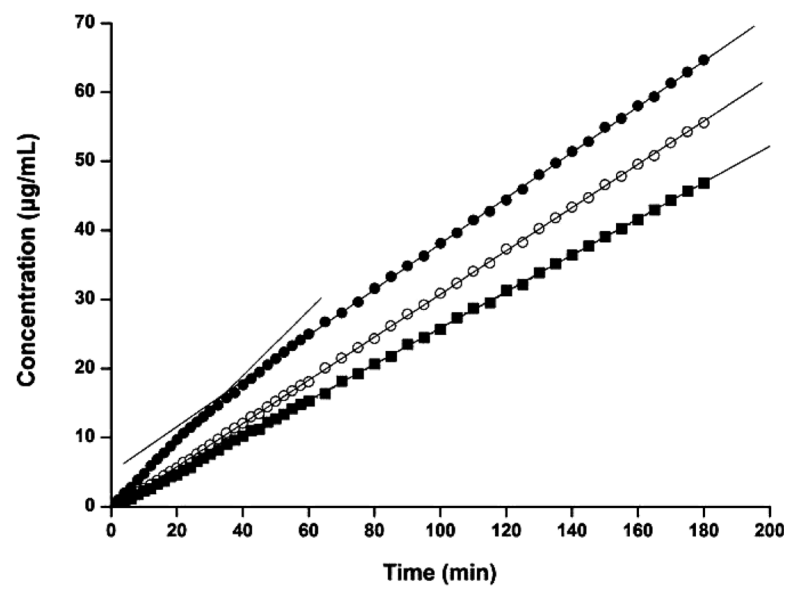

Fig. 5. Kinetic Solubility (a) and Intrinsic Dissolution (b) Profiles of Fluconazole Monohydrate ( $\mathbf{\square})$ and, Anhydrate Forms I (O) and II ( $)$ Prepared by SAS Process

Table 3. Solubility and Intrinsic Dissolution Rate (IDR) of Fluconazole Polymorphs Prepared by the SAS Process and Fluconazole Monohydrate (in Deionized Water at $25^{\circ} \mathrm{C}, n=3$ )

\begin{tabular}{|c|c|c|c|c|}
\hline Sample & $\begin{array}{l}\text { Solubility } \\
\text { measured }^{a)} \\
(\mathrm{mg} / \mathrm{ml}) \\
\text { 土S.D. }\end{array}$ & $\begin{array}{l}\mathrm{IDR}^{a)} \\
\left(\mathrm{mg} / \mathrm{min} / \mathrm{cm}^{2}\right) \\
\pm \text { S.D. }\end{array}$ & $\begin{array}{c}\text { IDR } \\
\text { constant }{ }^{f)} \\
(\mathrm{cm} / \mathrm{min})\end{array}$ & $\begin{array}{l}\text { Solubility } \\
\left.\text { estimated }{ }^{a, g}\right) \\
(\mathrm{mg} / \mathrm{ml}) \\
\pm \text { S.D. }\end{array}$ \\
\hline $\begin{array}{c}\text { Anhydrate } \\
\text { form I }\end{array}$ & $4.96 \pm 0.22^{b)}$ & $0.56 \pm 0.04$ & 0.114 & $5.02 \pm 0.24$ \\
\hline \multirow{2}{*}{$\begin{array}{c}\text { Anhydrate } \\
\text { form II }\end{array}$} & Maximum $^{c)} \quad 6.59 \pm 0.45$ & Initial $^{d)} 0.88 \pm 0.03$ & $3-$ & $7.88 \pm 0.27$ \\
\hline & Equilibrium $^{b)} 5.09 \pm 0.31$ & Final $^{e)} \quad 0.59 \pm 0.04$ & $4-$ & - \\
\hline $\begin{array}{l}\text { Mono } \\
\text { hydrate }\end{array}$ & $4.21 \pm 0.18^{b)}$ & $0.47 \pm 0.03$ & 0.112 & - \\
\hline
\end{tabular}

a) Mean \pm S.D. $n=3 . b$ ) Concentration of drug obtained from kinetic solubility profile after $48 \mathrm{~h} . c$ ) Maximum peak value obtained from kinetic solubility profile. d) The value obtained from intrinsic dissolution profile until $20 \mathrm{~min}$. e) The value obtained from intrinsic dissolution profile from 60 to $120 \mathrm{~min}$. f) The value calculated from Eq. 1. $g$ ) The value estimated from Eq. 2.

solubility experiment. The PXRD analysis of the excess drug of the anhydrate form I after solubility test revealed that the anhydrate form I and small amount of fluconazole monohydrate coexist (considered not present). Nevertheless, the maximum solubility of the anhydrate form I was maintained for $48 \mathrm{~h}$. This may be due to the anhydrate form I which can be dissolved in water still exist although the transformation to fluconazole monohydrate is occurred continuously.

As a result of check of polymorphic change using DSC and PXRD analyses after compression for preparation of disc, there was no polymorphic change although there was a little decreasing of crystallinity for the anhydrate form II (considered not present). The segmentation of the intrinsic dissolution profile of the anhydrate form II into initial and final segments was obtained by splitting the data in such a way that linear regression (Origin Lab Corp., OriginPro 7.5, U.S.A.) lines for each segment resulted in the best correlation coefficient $\left(R^{2}=0.999\right)$. IDR of anhydrate form I, II and fluconazole monohydrate were calculated from the initial part (from 0 to $20 \mathrm{~min}$ ) of intrinsic dissolution profile of each polymorph. ${ }^{27,28)}$ IDR of anhydrate form II was higher than that of anhydrate form I and fluconazole monohydrate $(p<0.001)$. A solid having a higher lattice free energy (i.e., a less stable polymorph) will tend to dissolve faster, because the release of a higher amount of stored lattice energy will increase the solubility and hence the driving force for dissolution. ${ }^{429)}$ Decrease of slope value in anhydrate form II was observed after $20 \mathrm{~min}$. As mentioned above, this may be due to the transformation from metastable anhydrate form II to most stable fluconazole monohydrate. DSC analysis of the surface of the disc after the dissolution test (after $3 \mathrm{~h}$ ) confirmed that almost of the anhydrate form II was transformed to fluconazole monohydrate although small amount of the anhydrate form II was remained (considered not present). Under sink conditions, the intrinsic dissolution rate (IDR) of a solid is defined by Eq. $1 .^{30-32)}$

$$
\mathrm{IDR}=k C_{s}
$$

where $k$ is the intrinsic dissolution rate constant, $C_{s}$ is the solubility of solid. The $k$ can be represented also the mass transfer coefficient, $k=D / h$, where $D$ is the diffusivity of the solid and $h$ is the thickness of the diffusion layer which depends on the geometry of the system and agitation conditions. ${ }^{33)}$ The $k$ of the most stable fluconazole monohydrate and anhydrate form I or II must be equal under identical hydrodynamic conditions, since $k$ depends on the diffusivity and thickness of the diffusion layer. If $k$ of fluconazole monohydrate and anhydrate form I or II is assumed to be equal, the Eq. 1 leads to

$$
\mathrm{IDR}_{\text {I or II }} / \mathrm{IDR}_{\mathrm{H}}=C_{\text {I or II }} / C_{\mathrm{H}}
$$

where $\mathrm{IDR}_{\mathrm{I}}$ or $\mathrm{IDR}_{\mathrm{II}}$ and $\mathrm{IDR}_{\mathrm{H}}$ are the mass fluxes for anhydrate form I, II and fluconazole monohydrate, respectively, and $C_{\mathrm{I}}$ or $C_{\mathrm{II}}$ and $C_{\mathrm{H}}$ are the solubilities of anhydrate form I, anhydrate form II and most stable fluconazole monohydrate, respectively. Thus, knowing the values for $\mathrm{IDR}_{\mathrm{I}}$ or $\mathrm{IDR}_{\mathrm{II}}$, $\mathrm{IDR}_{\mathrm{H}}$ and $C_{\mathrm{H}}$, the estimated value for $C_{\mathrm{I}}$ or $C_{\mathrm{II}}$ can be calculated from Eq. 2. The estimated solubility of anhydrate forms I and II was 5.02 and $7.88 \mathrm{mg} / \mathrm{ml}$, respectively (Table 3). This result showed that the anhydrate form I had no significant difference between measured and estimated solubility, while estimated solubility $(7.88 \mathrm{mg} / \mathrm{ml})$ of anhydrate form II was greater than the maximum concentration obtained from ki- 
netic solubility profile, which was $6.59 \mathrm{mg} / \mathrm{ml}$. The reason for having difference between measured and estimated solubilities of anhydrate form II, may be due to the transformation of anhydrate form II to stable fluconazole monohydrate before the solubility of metastable anhydrate form II could reach its equilibrium value. ${ }^{28)}$

In conclusion, ${ }^{13} \mathrm{C}$-SSNMR spectroscopy is a useful method for presenting of obvious differences in the chemical shift and peak splitting characteristics, reflecting a change in the molecular conformation, between fluconazole polymorphs, anhydrate forms I and II. Furthermore, the results of kinetic solubility and intrinsic dissolution tests indicated that the solubility and initial IDR of anhydrate form II was higher than that of anhydrate form I and fluconazole monohydrate, although the decrease in the solubility and dissolution rate of anhydrate form II is resulted by the transformation from anhydrate form II to most stable fluconazole monohydrate during dissolving procedure. These results indicate the need for quality control of polymorphism of fluconazole during pharmaceutical processing because the varying solubility and dissolution rates possible for different polymorphs of fluconazole may lead to varying degree of bioavailability.

Acknowledgments This study was supported by the National Research Foundation of Korea (NRF) grant funded by the Korea government (MEST) (No. 2008-0060533), Priority Research Centers Program through the National Research Foundation of Korea (NRF) funded by the Ministry of Education, Science and Technology (No. 2009-0093815) and a grant of the Korea Healthcare Technology R\&D Project, Ministry for Health, Welfare and Family Affairs, Republic of Korea (A080470).

\section{References}

1) Grant D. J. W., "Polymorphism in Pharmaceutical Solids," Chap. 1, ed. by Brittain H. G., Marcel Dekker, New York, 1999, pp. 1-33.

2) Singhal D., Curatolo W., Adv. Drug Deliv. Rev., 56, 335-347 (2004).

3) Pasquali I., Bettini R., Giordano F., Adv. Drug Deliv. Rev., 60, 399410 (2008).

4) Brittain H. G., Grant D. J. W., "Polymorphism in Pharmaceutical Solids," Chap. 7, ed. by Brittain H. G., Marcel Dekker, New York, 1999, pp. 279-330.

5) Brittain H. G., "Polymorphism in Pharmaceutical Solids," Chap. 6, ed. by Brittain H. G., Marcel Dekker, New York, 1999, pp. 227-278.

6) Bugay D. E., Adv. Drug Deliv. Rev., 48, 43-65 (2001).

7) Lubach J. W., Xu D., Segmuller B. E., Munson E. J., J. Pharm. Sci., 96,
$777-787$ (2007)

8) Yu L. X., Carlin A. S., Amidon G. L., Hussain A. S., Int. J. Pharm., 270, 221-227 (2004).

9) Zakeri-Milani P., Barzegar-Jalali M., Azimi M., Valizadeh H., Eur. J. Pharm. Biopharm., 73, 102-106 (2009).

10) “Physicians' Desk Reference ${ }^{\circledR}$ (PDR) Electronic Library,” Vol. 2004, Diflucan $^{\circledR}$, Medical Economics Company Inc., New Jersey, 2004.

11) Lo J. B., Mackay G. G., Puz M. J., U.K. Patent GB 2270521 (1994).

12) Gu X. J., Jiang W., J. Pharm. Sci., 84, 1438-1441 (1995).

13) Cyr T. D., Dawson B. A., Neville G. A., Shurvell H. F., J. Pharm. Bio. Anal., 14, 247-255 (1996).

14) MacSweeney S., Ph.D Thesis, Heriot-Watt University, U.K., 1999.

15) Dash A. K., Elmquist W. F., Anal. Prof. Drug Sub., 27, 67-113 (2001).

16) Janos K., Laszlo C., Csaba S., Jenone F., Ida D. J., Istivan H., Eva W. P., Judit N. B., Agnes P., U.S. Patent US 7094904 (2001).

17) Alkhamis K. A., Obaidat A. A., Nuseirat A. F., Pharm. Dev. Technol., 7, 491-503 (2002).

18) Desai S. R., Shaikh M. M., Dharwadkar S. R., Therm. Act., 399, 8189 (2003)

19) Caira M. R., Alkhamis K. A., Obaidat R. M., J. Pharm. Sci., 93, 601611 (2004).

20) Park H. J., Kim M. S., Lee S., Kim J. S., Woo J. S., Park J. S., Hwang S. J., Int. J. Pharm., 328, 152-160 (2007).

21) Bugay D. E., Pharm. Res., 10, 317-327 (1993).

22) Doherty C., York P., Int. J. Pharm., 47, 141-155 (1988).

23) Masuda K., Tabata S., Kono H., Sakata Y., Hayase T., Yonemochi E., Int. J. Pharm., 318, 146-153 (2006).

24) Šehić S., Betz G., Hadžidedić Š., El-Arini S. K., Leuenberger H., Int. J. Pharm., 386, 77—90 (2009).

25) Guillory J. K., "Polymorphism in Pharmaceutical Solids," Chap. 5, ed. by Brittain H. G., Marcel Dekker, New York, 1999, pp. 183-226.

26) Wurster D. E., Taylor P. W., J. Pharm. Sci., 54, 670 - 676 (1965).

27) Nogami H., Nagai T., Yotsuyanagi T., Chem. Pharm. Bull., 17, 499509 (1969).

28) Ono M., Tozuka Y., Oguchi T., Yamamura S., Yamamoto K., Int. J. Pharm., 239, 1-12 (2002).

29) Zhang G. G. Z., Zhou D., "Developing Solid Oral Dosage Forms," Chap. 2, ed. by Qiu Y., Chen Y., Zhang G. G. Z., Elsevier, Amsterdam, 2009 , pp. 25-60.

30) Kobayashi Y., Ito S., Itai S., Yamamoto K., Int. J. Pharm., 193, 137$146(2000)$.

31) Kim M. S., Jin S. J., Kim J. S., Park H. J., Song H. S., Neubert R. H. H., Hwang S. J., Eur. J. Pharm. Biopharm., 69, 454-65 (2008).

32) Kim J. S., Kim M. S., Park H. J., Jin S. J., Lee S., Hwang S. J., Int. J. Pharm., 359, 211-219 (2008).

33) Khankari R. K., Grant D. J. W., Thermochim. Acta, 248, 61-79 (1995). 